\title{
Customer Value as a Key Performance Indicator (KPI) and a Key Improvement Indicator (KII)
}

\author{
Djoko Setijono, Jens J. Dahlgaard \\ Department of Forest \& Wood Technology, School of Technology \&Design \\ Växjö University, Sweden \\ Division of Quality Technology \& Management, Linköping University, Sweden
}

\begin{abstract}
Purpose - The purpose of the paper is to develop existing tools or methodologies to measure customer value during acquisition and use, in such a way so that the measures concurrently indicate the level of performance and more "accurately" identify the improvement opportunities.

Design/methodology/approach - Customer value is indeed perceived by customers in the market (external customers) during acquisition, use, until the end of the product's lifetime. The producer is the entity that creates the products that the customers acquire or consume. Therefore, the producer needs to be aware, to interpret, and being actively involved in the creation of customer value. This view makes the "general agreement" that customer value is nothing else than customer perception in the market no longer relevant.

Therefore, ValMEA (Value Modes Effects and Analysis) offers a "balanced" perspective on customer value, by recognising that customer value exists in different "modes" on different stages of the product's life cycle. The link between different "modes" of customer value becomes an important basis to understand the contributions of producer activities on customer value.

Findings - Measuring customer value is necessary to capture the essential meaning of quality. However, the existing tools to measure customer value do not adequately manifest the concept of customer value itself. Therefore, the modification of these tools becomes the prerequisite to continuously improve quality performance. The measurement of customer value during acquisition and use is based on intangible aspects (cognitive judgement). Along the value stream, these measures are translated (transformed) into tangible aspects, which comprise aspects such as shorter lead-time, reduced defects, and lower costs.

Originality/value - The customer value measures complement the existing methodology such as Six Sigma, Lean Production, and Quality Function Deployment (QFD). The integration of customer value measures with these methodologies lead to the development of a customer-value-driven quality improvement framework, where improvement opportunities can be captured repetitively. The continuous quality improvement efforts can then be categorised into reactive (based on "waste" identification) and proactive (based on customer value measurements).

Keywords Customer value, performance indicator, improvement indicator, ValMEA, value map, PI matrix.

Paper type Conceptual paper

\section{Introduction}

Defining quality as fitness for use (Juran, 1962) rather than conformance to specifications implies an interpretation that products or services are meant to satisfy customer needs. It means that quality performance measures are no longer the monopoly of engineering in comparison with standards (i.e. product orientation) but they should also consider customer opinions (i.e. people orientation) since customers are the ultimate judges of quality (Garver, 2003). Therefore, Dahlgaard and Dahlgaard (2002) present the new TQM (Total Quality Management) metrology to measure quality from a customer perspective through satisfaction of both internal and external customers as well as
\end{abstract}


other stakeholders. Relying only on customer satisfaction might not be sufficient; at least it is an implicit interpretation of the reason that TQM continues its evolution in search for a "new" quality definition. According to Aune (in Edvarsson and Gustafsson, 1999), quality is "......maximum contribution to the health and happiness of all people involved in its production, use, destruction, and reuse. This with a minimum of total life cycle costs, assuming a minimum use of energy and other resources and with generally acceptable consequences for the society and environment at large". This definition of quality consists of two important elements, i.e. contribution and cost. Contribution refers to what customers receive and cost refers to what customers and other stakeholders sacrifice. Summation or trade-off between what customers receive (e.g. benefits) and what they sacrifice (e.g. cost) determines customer value of a product or service (Bounds et al, 1994; Dumond, 2000). Nichols (1993) states that the focus on customer value can be regarded as the fourth phase of the TQM evolution.

According to Juran (1951), the value of quality is a composite of value inherent in the design and value inherent in the conformance to that design. This means that improving design quality and conformance quality will likely increase value. A study in a Swedish wood-flooring manufacturing company indicates that about $80 \%$ of the total quality costs in the company are failure costs (both internal and external), and $20 \%$ is the sum of prevention and appraisal costs (Setijono, 2005). We may then perceive that there is a high amount of "waste" (i.e. defects, non-conformities, inefficiencies, etc) inside the company. The findings from interviews and observations conducted in the company suggest that external failure costs is mainly caused by not adequately considering the second and third customer tiers, i.e. the installers and end-users as shown in figure 1. The manufacturer (M) fulfils a demand chain, which consists of three different types of customers, i.e. dealers (D), installers (I), and end-users (U). The dealers are the main or direct customers (first tier), while installers and end-users are the indirect customers. Since complaints regarding product quality are usually generated by these customers through the dealers or directly to the manufacturer (see figure 2), while internal failures are mainly caused by a reactive way of managing quality and a lack of customer-supplier awareness inside the company. Therefore, there is a need to develop a framework to improve quality attributes that are valuable for customers, and which addresses both internal and external causes of quality-related problems.

\section{Take in figure 1}

Figure 1. Supply and demand chain

\section{Take in figure 2}

Figure 2. Complaint process

Despite the fact that there are many different definitions about customer value, Higgins (1998) captures that customer value and customer satisfaction is not a disconnected link. There are different models that attempt to describe the link between customer value and customer satisfaction, and even with other performance measures such as customer loyalty, profitability, and competitiveness. Most literature, especially in marketing, discuss the influence of customer value on purchasing decisions or discuss customer value in a service context. However, few discuss the influence of customer value in relation with product in use-context and how customer value may drive improvements of product and process quality. It is the aim of this paper to further develop the tools to measure customer value during acquisition and use, in such a way that the opportunities to improve product quality can be identified simultaneously.

The paper is organised in the following structure: first, the author provides a brief theoretical review on customer value and customer satisfaction. Second, a "balanced" perspective on customer value is presented. Third, the "new" way of measuring customer value to indicate performance as well as to identify improvement opportunities is described. The author also gives an example regarding the application of the measures. The development of a customer-value-driven quality 
improvement framework is described thereafter. The paper then finalises with reflections and conclusions.

\section{Theoretical background}

\section{Customer value}

"Any definition of value must account for the inclusion of total benefits, including direct and indirect benefits derived from attributes and consequences, that arise from partner (seller-buyer) activities and behaviours, less total direct and indirect costs, and be determined from the customer perspective" (Simpson et al, 2001, pp. 121). Woodruff (1997; in Simpson et al, 2001) defines value as a customer's perceived preference for and evaluation of those product attributes, attribute performances, and consequences arising from the use that facilitate (or block) achieving the customer's goals and purposes in use situation. Dumond (2000) summarised the common themes about customer value that it is "linked to the use of product or service", "perceived by the customers rather than objectively determined by seller", and "usually involves a trade-off between what customer receives, e.g. quality, benefits, worth, and what he or she gives up to acquire and use a product or service, e.g. price, sacrifices". Then, customer value is the summation of benefits minus the sacrifices that result as consequence of a customer using a product or service to meet certain needs. This definition moves away from the notion that value is something inherent to the product or service toward the notion that value is determined in the context of customer use (Bounds et al, 1994).

According to Khalifa (2004), the way of defining customer value can be grouped into three categories: value components model, utilitarian or benefits-costs ratio model, and means-ends model. In term of value components model, value is interpreted as the performance or physical characteristics of the product that: a) must-be present, b) expected to be present, and c) delight the customers if the characteristics are present. According to the utilitarian model, customer value is the difference (or ratio) between total benefits and total sacrifices. Value, according to means-ends model, is the accomplishment of favourable ends through the acquisition and the use of a product as the means. Even though these models are (to some extent) different, they are not mutually exclusive but overlap to each other, which is then utilised by Khalifa (2004) to build an integrative configuration of customer value concept by first "expanding" each basic category of customer value model.

\section{Value map}

The customer value map, introduced by Gale (1994), is a tool to analyse whether a product or a company has provided superior customer value by plotting market perceived quality (MPQ) against market perceived price (MPP) on a two-dimensional chart (see figure 3). MPQ is the sum of multiplications between performance scores ratio (R) and importance weight (W) on each quality attribute, for example safety, durability, and availability. MPP is calculated as MPQ; the only difference is that MPP is applicable on price attributes such as purchase price, trade-in allowance, resale price, and interest rates. Performance and importance scores data are usually collected using surveys or interviews. Performance scores represent customers' cognitive judgement on product attributes, measured by e.g. a 1-7 scale, while the importance weight usually is measured using a 0100 scale, which represents how the various product attributes are weighted in the customer's decision.

$$
\begin{aligned}
& M P Q=\sum_{i=1}^{n} R_{i} * W_{i} \\
& M P P=\sum_{j=1}^{m} R_{j} * W_{j}
\end{aligned}
$$


Where:

$\mathrm{Ri}$ : the ratio between the performance score $(\mathrm{P})$ of a product and the performance score of the competing product(s), on the quality attribute $\mathrm{i}$.

$\mathrm{Wi}$ : the weight (importance) of quality attribute $\mathrm{i}$.

$\mathrm{i}: 1,2,3, \ldots \mathrm{n}$

$\mathrm{Rj}$ : the ratio between the performance score $(\mathrm{P})$ of a product and the performance score of the competing product(s), on the price attribute $\mathrm{j}$.

$\mathrm{Wj}$ : the weight (importance) of price attribute $\mathrm{j}$.

$\mathrm{j}: 1,2,3, \ldots \mathrm{m}$

Take in figure 3

Figure 3. Customer Value Map

Gale (1994, pp. 83) illustrates the fair value zone, i.e. the area where the ratio between MPQ and MPP is approximately 1. Within this zone, products or firms provide "fair" customer value, meaning that customers perceive a product with a certain quality level worth to be bought at its current price level. Outside this zone, a product or a firm provides more or less customer value (depending on the location of the point). A product or firm that provides better customer value is more competitive in the market compared to its competitors.

\section{Performance-Importance (P-I) matrix}

Garver (2003) lists the use of the P-I matrix as a tool to: evaluate a firm's competitive position in the market, to identify improvement opportunities, and to guide strategic planning. The P-I matrix utilises customer satisfaction data, where for each product (or service) attribute, the average score of performance is plotted against the average importance score using a $2 \times 2$ matrix (see figure 4). Actual performance is measured using e.g. a 1-7 or a 1-5 scale, while relative performance can be measured by using gap analysis, comparative scales, or actual performance (Garver, 2003).

Take in figure 4

Figure 4. Performance-Importance (P-I) Matrix

\section{Value Modes Effects \& Analysis: a "balanced" perspective on customer value}

The statement "customer value, which is something that is determined in the context of customer use" refers to what is called received value. "Customer value, which is something that is perceived by customers rather than determined by the seller", indicates that the customer already perceives the value of a product or a service during the acquisition (purchase) stage. Tracy and Wiersima (1995; in Khalifa, 2004) argue that the components of customer value include low price, speedy response, premium service, and high quality. These components of customer value are similar to what is labelled as "value added", i.e. higher product or service quality, faster delivery, and lower cost, which are discussed within the manufacturing or production context by the concept of lean production, lean sigma, or lean thinking (see e.g. Jiju et al, 2004; Wood, 2004), and Grönroos (2000; in Khalifa, 2004) who suggests that customer perceived value equals to core value \pm added value. The added value is positive when the additional services can be provided without unnecessary or unexpected costs, while it can be negative (and destroy the core value) when the contacts and processes in the customer relationship are not managed as services or when the additional services cause unnecessary (unexpected) costs.

The description above exposes the contradictions towards the "general agreement" about customer value in most literature or according to a majority of researchers (summarised by Khalifa, 2004), which suggest that customer value is determined by customers' perception (in the market place) not by suppliers' assumptions or intentions (in the factory). The "findings" suggest that producers or manufacturers give some efforts to understand customer value and (in a large extent) 
being involved in the creation of customer value; therefore the "general agreement" should be challenged. It seems clear that the "raw" ingredients of customer value are high quality, faster response or delivery, and lower cost/price but it totally depends on the customers themselves to "transform" these raw ingredients into something valuable as well as to judge whether a product or service is valuable or not.

As an implication, customer value may exist in the following "modes": added value, perceived value, and received value depending on which context the value is defined. Added value is the characteristics of high quality, faster delivery, and lower cost. Perceived value is a trade-off between benefits and sacrifices perceived by the customer in a supplier's offering (Eggert and Ulaga, 2002) or customer's overall assessment of the utility of a product based on the perceptions of what is received and what is given (Zeithaml et al, 1988; in Edvardsson and Gustafsson, 1998). Received value is the customer value in acquisition and use context (Horovitz, 2000; in Khalifa, 2004) and it is about customer's experiences (Lanning, 1998; in Khalifa, 2004). According to Parasuraman et al (1988; in Eggert and Ulaga, 2002), customer satisfaction is a feeling, the result of a comparison between perceived performance and one or more comparison standards, such as expectations.

It is difficult (if not impossible) to separate customer value and satisfaction. Therefore, customer satisfaction will always be in conjunction with customer value, either it becomes the predecessor of value (see Edvardsson and Gustafsson, 1999; Dumond, 2000; Khalifa, 2004) or the successor of the value (Oh, 1999; van der Haar et al, 2001; Dahlgaard and Dahlgaard, 2002; Eggert and Ulaga, 2002; Spitteri and Dion, 2004; Liu et al, 2005). In the purchase or buying context and the service context, customer satisfaction becomes the successor of perceived value; while in the product use context, satisfaction is the predecessor of received value because the customer should be first "convinced" that the product has both the necessary and the additional characteristics as he/she expected before he/she believes that the product is the "right" means to achieve his/her ends (goals). Figure 5 provides a conceptual link of how added value (in manufacturing) turns to value received by customers. The existence of this link makes ValMEA consistent with the existing theory about customer value that the "....categories of value definitions are not mutually exclusive" (Khalifa, 2004; pp. 648).

\section{Take in figure 5}

Figure 5. Links between added value and received value

Perceived value, customer satisfaction, and received value are the "representation" of value during acquisition (purchase) and use. These "representation" of value accommodate the three models to categorise customer value definitions (i.e. value components model, utilitarian model, and means-ends model) and explain the fundamental difference between them. The term value in the means-ends model refers to a cognitive judgment [about the accomplishment of a goal], while the same term refers to a feeling [of satisfaction] and an assumption [that the benefits are more than the sacrifices], according to the value components model and the utilitarian model respectively. In this respect, the definitions of customer value are based on intangible aspects, i.e. perception. This perception is then understood and transformed into tangible attributes, such as quality (the function, the fit, and the form), that are built into a product (at a lower costs and shorter time) in order to help customers accomplish their goals. The interpretation (transformation) of customer value from being intangible to be tangible makes ValMEA a more "balanced" perspective, in the sense that the contributions and involvement of the producer into the creation of customer value are also recognised.

The effect-and-analysis part of ValMEA can be explained through the following interpretations. The received value is the "ultimate" value for the users, where the acquisition and ownership of a product fulfilled their goals. Therefore, information about received value becomes crucial inputs for 
the producers to improve product quality. Perceived value is important for the manufacturers in order to satisfy the needs of their customers (end users or resellers) by increasing the performance of their product or service quality. Added value becomes enablers towards the creation of customer value, where quality is one of the essential elements. If quality is such an important component of customer value, then "how should we define quality so that it reflects the concept of customer value?". The following reflection should be regarded as an attempt to answer the question. Quality is the degree of existence [dissatisfactory, satisfactory, or delight] of product or service attributes which are considered [perceived or judged] as valuable [facilitate the accomplishment of goals] and which are attainable at a fair cost.

\section{Measuring customer value during acquisition \& use}

Perceived customer value is the "representation" of customer value during the acquisition, which can be measured using the customer value map. However, Gale (1994) does not further discuss the way to determine the zone of fairness, i.e. the zone where the customers perceive a fairness or balance between the quality (benefits) and price (sacrifice). Therefore, the fair value zone must first be determined. Additionally, the value map mainly highlights customer value as a factor that influences purchasing decisions and not customer value in a use-context. However, by "extending" the term "price" to "life cycle cost", it can be argued that the customer value map is also applicable in a use-context.

The value map is useful to indicate: 1 ) whether the value of a product is perceived as "superior" or "inferior" compared to other competing products, and 2) if the value of an individual product is perceived as fair, low value, or high value. However, the value map is inadequate to indicate what product attributes must be improved to enhance the value provided to the customers. Therefore, the value map should be combined with a performance-importance (P-I) matrix to identify improvement opportunities, so that the product (quality) attributes that cause the "inferiority" on customer value can be identified. The "problem" is, the "as it is" P-I matrix, do not adequately accommodate the concept of customer value. We then need to modify the existing P-I matrix by accommodating a value components model, such as the Kano model (Kano, 2001).

\section{Determining the zone of customer value fairness}

According to Monroe (1990; in Padula and Busacca, 2005), the value of a product comprises acquisition value (AV) and exchange value (EV). Acquisition value is about customer's perception of what he/she "gets" and "gives". The acquisition value is more popular under the "label" perceived customer value (PCV), where PCV is defined as the ratio between Market Perceived Quality (MPQ) and Market Perceived Price (MPP). Then:

$$
P C V=\frac{M P Q}{M P P}
$$

The exchange value represents the perceived merit of the offer or deal (Monroe, 1990; in Padula and Busacca, 2005), which manifests in the form of price, P, (Padula and Busacca, 2005). Therefore:

$$
E V=P
$$

Then, the zone of fairness can be derived mathematically by assuming that: 1) the value exchanged by a customer is equal to the value that he/she gets in return (acquired), and 2) a product with higher product quality can be sold at a higher price.

Based on the first assumption, we may then define the following equation: 
Without a modification, this equation will be difficult to implement because PCV and EV have different unit of measurements, in which PCV is dimensionless while EV is stated by a currency, e.g. $\$$, $£$, etc. To solve the problem, the price, as the manifestation of exchange value, should be conceptualised as a multidimensional construct rather than a one-dimensional construct (Padula and Busacca, 2005), which means that the customers evaluate actual price in comparison with the utility (U) of a product (either in a subjective or relative way). In a subjective price evaluation, utility is defined as the willingness to pay, where the customers might be willing to pay more or less than the price expected by the seller. In case of relative price evaluation, utility is defined as the worth of the product, which represents customers' judgement of the fair price to acquire a product. The price that is considered as fair might be equal or less than the actual price offered. In both cases, utility is dependent on customer's judgment about the product he/she acquired. The customers might judge the quality of the product (in comparison with other competing products) to determine the utility (worth) of a product (Mochimoto and Ohfuji, 2005). Then, the multidimensional conceptualisation of price requires us to reformulate equation (5) into:

$$
E V=\frac{U}{P}
$$

If utility is defined as "willingness to pay", the ratio between utility and actual price can be between zero ( 0$)$ and positive-indefinite $(+\infty)$. However, when utility is defined as "worth", the ratio between utility and the actual price will be between 0 and 1 because the relative utility assumes that the actual price is assumed as the maximum amount of money that the customers are willing to pay. Therefore, the second assumption allows that customer's willingness to pay can be less or more than actual price.

If we compare equation (3) and equation (6), it seems that we can verify the first assumption (i.e. the equality between acquisition value and exchange value), due to the convergence in the meanings of utility. In the field of economics, utility is defined as the satisfaction due to the consumption of products, which is quite similar in the field of quality management, where utility reflects the ability of a product to satisfy users or customers. This ability depends on the function, fit, and form of the product. The customers' judgment on these aspects determines the way customers perceive the quality of the product.

The zone of fairness may be determined with the help of the data described in Gale (1994, pp. 304), where the data about market perceived quality (MPQ) of different companies have been collected and stored in the PIMS database (Profit Impact of Market Strategy). Gale's classification suggested that if firms are categorised as "about the same quality", the market perceived quality lies between 0.92 and 1.08. The selling price of the product from these firms varies within the range of 0.97 to 1.04 of the current price level.

We are then able to determine that $0.92 \leq M P Q \leq 1.08$ and $0.97 \leq \frac{U}{P} \leq 1.04$. While the MPP is estimated using the following equation:

$$
M P P=\frac{M P Q}{U / P}=M P Q * \frac{P}{U}
$$

Where the result is shown in table I.

Table I. The estimation of MPP

Take in table I 
The zone of satisfaction is the distance between the upper value line and the lower value line, where the equations for these lines are shown in table II. In another word, the zone of satisfaction is actually the total "distance" between MPQ and MPP on lower and upper sides, but for the purpose of simplification, the distance between MPQ and MPP for each side is assumed to be equal. Therefore, the zone of fairness may then be defined as the interval within $y=x \pm 0.03$

Table II. Determining the zone of fairness

Take in table II

\section{Life Cycle Costing (LCC) and "Customer Cognitive Judgement" (CCJ)}

ValMEA recognises the difference between perceived and received value. This makes the ordinary value map, suggested by Gale (1994), inadequate to accommodate and capture the received value in a use-context. Therefore, the author suggests that the price-related attributes should be extended into life cycle cost (LCC) related attributes, and recommend the use of "Customer Cognitive Judgement" (CCJ) in order to distinguish from the term "Market Perceived" (MP) introduced by Gale.

The new definition of quality (Aune op cit) refers to the importance of minimum life cycle costing (LCC), which includes the cost of ownership during the lifetime of a product. The concept of LCC becomes important when customer value is identified not only in a purchase-context but also in a use-context. It also becomes critical for a manufacturer when market competition includes both competitor and substitute products.

Taking wood flooring products as an example, the manufacturer of wood flooring products is facing the market competition from other wood flooring products as well as substitute products such as laminate floors, carpets, and plastic floors. A study by Moussatche and Languell (2001) shows that the LCC of wood-based flooring materials is significantly higher than other flooring materials, and the difference is mainly caused by high costs after the purchase (acquisition) of the product.

There are several LCC models, which are categorised either as general or specific, according to products or industry types (Dhillon, 1989). One of those models describes LCC as the sum of price, installation cost, operation \& maintenance cost, and disposal cost.

\section{Value-driven P-I matrix}

It is assumed that a quality attribute satisfies the customer if customer's perception is greater or at least equal to expectations. In the P-I matrix, this perception is represented by the "performance" (P) axis and the expectation is represented by the "importance" (I) axis. Performance is the level of satisfaction on quality attributes, while Importance is the significance of the quality attributes of the product or the presence of characteristics. Therefore, the P-I matrix (which actually is another form of a gap analysis tool) can be used as a tool to analyse customer satisfaction on the various product quality attributes.

According to Khalifa (2004), the Kano model (Kano, 2001) is a well-known value components model, which includes three components of value: dissatisfiers (must be), satisfiers (more is better), and delighters (exciters). Therefore, customer satisfaction seems to be an important indication whether the customers, during the use of a product, regard the attributes of a product as valuable or not.

Using merely the P-I matrix as a customer satisfaction analysis tool does not seem to fulfil the condition that satisfaction is linked to value. However, because the P-I the matrix does not recognise the zone of satisfaction (see figure 6), an area or interval on the P-I matrix where product 
attributes can be categorised as satisfiers. This area is analogue to the zone of fairness (in the value map), if we define "fairness" as the absence of gap between performance and importance. Hence, satisfaction is a condition where the difference between $\mathrm{P}$ and $\mathrm{I}$ is equal or near to 0 . Outside this zone of satisfaction, product attributes are categorised as delighters if their performance is larger than their importance, while these attributes are dissatisfiers for the customers if the performance is lower than the importance.

The use of cells in order to indicate improvement opportunities is not quite accurate because it "neglects" the "zone of fairness", where the "performance" is approximately at the same level as "importance". Therefore, value components should be incorporated into the P-I matrix, and after determining the zone of satisfaction, the attributes which need to be improved can be identified.

Take in figure 6

Figure 6. P-I matrix incorporating value components model

Assuming that the product (quality) attributes are independent to each other, the zone of satisfaction (ZOS) may be determined in a similar way as the control limits of a control chart, where inside the zone of satisfaction, the difference between the performance and importance of product attributes is regarded as random variation. The exact value of this difference varies for each attribute, but still "within its natural variation". Hence, ZOS is calculated as plus/minus three times its standard deviations.

For each of quality attributes, the average difference (D) between performance score $(P)$ and the importance score (I) can be further defined as:

$$
D_{j}=P_{j}-I_{j}=\sum_{i=1}^{n}\left(\frac{P_{i}}{n}\right)-\sum_{i=1}^{n}\left(\frac{I_{i}}{n}\right)
$$

Where:

$D_{j} \quad$ : The difference between the performance score and importance score of quality attribute $j$

$\mathrm{P}_{\mathrm{j}} \quad$ : The average performance score of product (quality) attribute $\mathrm{j}$

$\mathrm{I}_{\mathrm{j}} \quad$ : The average importance score of product (quality) attribute $\mathrm{j}$

$\mathrm{m} \quad$ : The total number of quality attributes

$\mathrm{P}_{\mathrm{i}} \quad$ : The performance score of a certain product attribute, which is given by customer $\mathrm{i}$

$\mathrm{I}_{\mathrm{i}} \quad$ : The importance score of a certain product attribute according to customer $\mathrm{i}$

$\mathrm{n} \quad$ : The total number of customers

The construction of the control chart to plot multiple quality attributes is based on the assumption that if the values produced and delivered are in balance with expectations then the average difference (D) [between performance and importance] of each quality attribute is equal to zero. The centre line of the control chart is under the same assumption also equal to zero. The upper limit of ZOS ( $\left.Z_{\text {usper }}\right)$, and the lower limit of $\mathrm{ZOS}\left(\mathrm{ZOS}_{\text {lower }}\right)$ of the control chart can then be determined as:

$$
\begin{gathered}
Z O S_{\text {upper }}=3 \sigma \\
Z Z_{\text {lower }}=-3 \sigma
\end{gathered}
$$

We may estimate $\sigma$ by calculating $s$, where: 


$$
S=\sqrt{\frac{\sum_{j=1}^{m}\left(D_{j}-D\right)^{2}}{n^{*}(m-1)}}
$$

In which:

$$
D=\sum_{j=1}^{m} \frac{D_{j}}{m}
$$

Incorporating these value components into the PI matrix shows that quality improvement opportunities are no longer indicated by a "major weakness" cell but showed by the area of dissatisfaction. The area of dissatisfaction can be further categorised into major or minor priority (see figure 7).

\section{Take in figure 7}

Figure 7. Classifying improvement priorities in the area of dissatisfaction

Adopting the control chart principles should also take into consideration the fact that a certain quality attribute might have different impact on different customers or customer segments, in the sense that a quality attribute may dissatisfy one customer (segment) but may delight another. Therefore, the construction of the control limits in (9) and (10) should be complemented by a control chart to control the individual customer satisfaction measurements on each of the $m$ quality attributes. The centre line in this control chart is also equal to zero but $\sigma$ is here estimated by (13) below:

$$
S=\sqrt{\frac{\sum_{i=1}^{n} \sum_{j=1}^{m}\left(D_{i j}-D_{j}\right)^{2}}{m^{*}(n-1)}}
$$

Where:

$\mathrm{D}_{\mathrm{ij}} \quad$ : The difference between the performance score and the importance score on quality attribute $\mathrm{j}$ given by customer i

\section{Example of application}

Let's assume that there are two competing products in a certain market segment, product $\mathrm{A}$ and product $B$. There are $n_{1}$ (let $n_{1}=100$ ) customers of product $A$ and $n_{2}$ (let $n_{1}=n_{2}$ ) customers of product $\mathrm{B}$ whom were asked about the importance and performance of each product attribute, i.e. quality attributes $\left(Q_{1}, Q_{2}, \ldots\right)$ and cost attributes $\left(C_{1}, C_{2}, \ldots\right)$, e.g. price, operational and maintenance cost, of each product and their responses are measured using a 1-7 scale (7 is the maximum on the scale). Prior to data collection, it is necessary to have an "agreement" on what a low or high measurement scale may indicate. For example: a low importance score on a product (or quality) attribute might indicate that this attribute is less or not important. A similar condition (low importance) in a cost attribute might be interpreted as that it is less or not important whether a certain cost attribute has a low cost or not. A low performance score on a product (quality) attribute can be used to indicate a poor performance as well as that a certain cost attribute is expensive. The average importance and performance scores for both product A and B is recorded in table III.

Table III. Average score of customer's importance and performance 
The next step is to calculate customer value of each product. In this case, the importance weight is determined from importance scores. The importance weight of the $j$-th attribute $\left(\mathrm{W}_{\mathrm{j}}\right)$ is determined by the ratio between the $j$-th normalised importance score $\left(I_{\text {norm }}(j)\right)$ and total normalised importance score. The normalisation process, which is analogue to the normalisation procedure as described in e.g. Antony (2000) and Best (2004), is expected to reduce the dependence on the measurement scale, so the results are comparable either we use a 1-7 scale or a 1-10 scale. Equation (14) shows the calculation of the normalised importance score of the $j$-th attribute, where $I_{j}$ is the importance score of the $j$-th attribute from each product, $I_{\max }$ is the maximum (highest) importance score and $I_{\text {min }}$ is the minimum (lowest) importance score. Since we are using a 1-7 scale, then $I_{\max }$ and $I_{\min }$ is 7 and 1 respectively. Table IV shows the way of determining the importance weight of each product attribute.

$$
I_{\text {norm }}(j)=\frac{I_{j}-I_{\min }}{I_{\max }-I_{\min }}
$$

Table IV. Calculating the importance weight

Take in table IV

Table $\mathrm{V}$ shows the score of customer cognitive judgement regarding quality and cost of product A, where $\mathrm{R}$ is the ratio between the performance of product $\mathrm{A}$ relative to the performance of product $\mathrm{B}$ on quality or cost attributes. The customer cognitive judgement on quality (CCJQ) or customer cognitive judgement on cost (CCJC) of product $A$ is the sum of multiplications between the importance weight $(\mathrm{W})$ and the performance of product $\mathrm{A}$ relative to product $\mathrm{B}(\mathrm{R})$ on the $j$-th quality-related or cost-related attribute. The CCJQ and CCJC for product B or firm Y is shown in table VI but in this case we use 1/R to indicate the performance of product B relative to product A.

The CCJQ for each product or firm is then plotted against its CCJC in order to identify the product or firm performance in providing customer value. Figure 8 provides a visualisation of the competitive position of each product in providing customer value. It indicates that product B provides better customer value and product A provides worse customer value, which means that product B gives more "value for money". If product A and B are produced by different companies, then we may perceive that the manufacturer of product $B$ is more competitive than the manufacturer of product A.

\section{Table V. CCJQ and CCJC of product A Take in table $V$ \\ Table VI. CCJQ and CCJC of product B Take in table VI}

Take in figure 8

Figure 8. Value Map

\section{Identifying improvement opportunities}

Customer value can be increased through (product) quality improvement or alternatively through cost reduction. Considering that improving quality may also lead to cost reduction, then quality improvement is a must-be need to increase customer value. Improving quality proactively requires 
an identification of improvement opportunities through, in this case, customer satisfaction analysis. Then, the next step after analysing the customer value is to analyse customer satisfaction using the control chart of multiple quality attributes (by plotting the average difference between performance and importance score for each attribute) or using P-I matrix in order to identify the quality improvement opportunities, which is performed by plotting the performance score on the selected quality attributes of a product against its importance score. Although it is possible to analyse the performance and importance of the attributes of both product $A$ and $B$, this paper will only describe the customer satisfaction analysis of product $\mathrm{A}$, mainly due to a consideration that the customer value provided by product $A$ has been judged as lower than the customer value provided by product B.

We first need to calculate the difference between performance and importance for each attribute ( $D_{j}$ ) according to equation (8), and then calculate the average and the standard deviation before we can define the control limits. Table VII shows the calculation of $D_{j}$.

Table VII. Difference between performance and importance scores of product A Take in table VII

Using equation (12) and (11), we estimate that the value of $\mathrm{D}$ and $s$ are 0.263 and 0.064 respectively. Then, based on equation (9) and (10), we could construct a control chart for multiple quality attributes, where the UCL $=0.1915$ and the LCL $=-0.1915$, which is shown graphically by figure 9. It is also possible to analyse the customer satisfaction using P-I matrix, by plotting the importance score of an attribute against its performance score (see figure 10). Both the control chart and the P-I matrix indicate that there are several attributes outside control limits or zone of fairness respectively. The quality attributes Q1, Q3, Q5, Q6, Q9, and Q10 are the delighters, while Q8 seems to be a satisfier. Since the performance of attribute Q2, Q4, and Q7 are lower than their importance, then these attributes should immediately be improved. When further analysing these attributes it may be good help to use the control chart for the individual customer measurements. For this purpose, (13) is used to estimate $\sigma$ in (9) and (10).

Take in figure 9

Figure 9. Control chart to plot multiple quality attributes

Take in figure 10

Figure 10. P-I matrix for product A

Hence, it is obvious that the value map can be used in conjunction with the modified P-I matrix and/or the control chart for multiple quality attributes. However, for a thorough analysis, it would be beneficial to complement the value map and the P-I matrix with a complaint report in order to provide more "evidence" or "confirmation" for the decision to improve quality attribute Q2, Q4, and Q7. The next step is to track, analyse, and improve the process that is related with these attributes. Internal defect reports and identification of inefficiencies will support the process and production improvements.

\section{Customer-value-driven quality improvement framework}

The framework of quality improvement (figure 11) starts with an assessment of the product's competitiveness in providing customer value relative to competition (and eventually substitute products), using a Value Map. The next step is to identify which product attributes need to be improved. The firm might also complement (or "confirm") the findings with complaint data from external customers and internal data regarding defects. Next, trace to the processes that are "responsible" for the quality attributes. During production, the inefficiencies (e.g. delays) occurred also deserve attention for improvement efforts. 
In figure 11, it can be recognised that customer value has a direct influence on product quality improvement and deployed further to process and production (see vertical arrow). Performing quality improvement in this way recognises and increases the benefits of using improvement tools like Quality Function Deployment (QFD). By integrating the customer value map and the P-I matrix (or D-chart) into QFD, the customer voices can be captured repetitively, which then becomes a manner of continuous improvement. Meanwhile, continuous improvement can also be done by identifying and eliminating waste in internal operation (see horizontal arrow) using for example the Lean (Six) Sigma method. According to George et al (2004), Lean (Six) Sigma is a powerful improvement methodology, which combines the strengths or advantages of Six Sigma (see e.g. Antony et al, 2004) and the lean concept (see e.g. Wood, 2004) to improve both quality and process flow (speed). Through its four keys (i.e. delighting customers with quality and speed, process improvement, teamwork, and decisions based on data and facts), Lean Sigma becomes a way for manufacturers in providing customer value.

Take in figure 11

Figure 11. Customer-value-driven quality improvement frameworks

\section{Conclusions}

Calculation of customer value is not merely a way to indicate a company's competitive advantage relative to competitors but it may also become a driving factor to continuously improve product and process quality. Customer value may drive continuous improvement of product and process quality because it exists in several modes (i.e. added value, perceived value, and received value), which is caused by the facts that customer value occurs in several contexts and the term "customer" usually refers to a heterogeneous groups of people (market segments) and sometimes involves several customer tiers (e.g. dealers, service providers, and end users). Identifying customer value (in a purchase/use and manufacturing contexts) lead to both reactive and proactive improvements. These two types of improvements are not mutually exclusive but complement each other in order to construct a customer-value-driven quality improvement framework.

The customer-value-driven quality improvement framework integrates the tools to identify customer value (Value Map) and customer satisfaction (Performance-Importance (P-I) Matrix or Dchart) with the existing methodologies in managing quality, in this case QFD and Lean Six Sigma. Due to the existence of value in different modes (ValMEA), the ordinary value map and P-I matrix need modifications, as suggested in this paper, in order to better capture the essence of customer value to drive quality improvements.

\section{References}

Antony, J. (2000), "Multi-response optimisation in industrial experiments using Taguchi's loss function and Principal Component Analysis", Quality and Reliability Engineering International, Vol. 16, issue 1, pp. 3-8.

Antony, J., Foutris, F., Banuelas, R, Thomas, A. (2004), "Using Six Sigma", IEEE Manufacturing Engineer, Vol. 83, No. 1, pp. 10-12.

Aune, A. (1999), "Leadership and management for quality - and a discipline called quality technology", in

Edvardsson, B., Gustafsson, A. (Eds), The Nordic School of Quality Management, Studentliteratur, Lund, pp. 62-77.

Best, R.J. (2004), Market-based management: strategies for growing customer value and profitability, Upper Saddle River, NJ, Prentice Hall.

Bounds, G., Yorks, L., Adams, M., Ranney, G. (1994), Beyond Total Quality Management: toward the emerging paradigm, McGraw-Hill, New York.

Dahlgaard, J.J., Dahlgaard, S.M.P. (2002), "From defect reduction to reduction of waste and customer/stakeholder satisfaction (understanding the new TQM metrology)", Total Quality Management, Vol. 13, No. 8, pp. 1069-1085.

Dhillon, B.S. (1989), Life Cycle Costing, Gordon and Breach Science Publishers, USA 
Duke, C.R., Mount, A.S. (1996), "Rediscovering Performance-Importance Analysis of Products", Journal of Product and Brand Management, Vol. 5, No. 2, pp. 43-54

Dumond, E.J (2000), "Value Management: an underlying framework", International Journal of Operations \& Production Management, Vol. 20, No. 9, pp. 1062-1077.

Eggert, A., Ulaga, W. (2002), "Customer-perceived value: a substitute for satisfaction in business markets?", Journal of Business and Industrial Marketing, 17(2/3), pp. 107-118.

Garver, M.S. (2003), "Best practices in identifying customer-driven improvement opportunities", Industrial Marketing Management, 32, pp. 455-466.

Gale, B.T. (1994), Managing Customer Value, The Free Press, New York.

George, M., Rowlands, D., Kastle, B. (2004), What is lean six sigma?, McGraw-Hill, New York

Higgins, K.T. (1998), "The value of customer value analysis: customer value analysis becomes the starting point in marketing research", Marketing research, Vol. 10, No. 4, pp. 39-44.

Juran, J.M (1951), Quality Control Handbook, McGraw Hill Book Company, Inc., New York.

Juran, J.M. (1962), Quality Control Handbook, 3rd edition, McGraw Hill.

Kano, N. (2001), "Life Cycle and Creation of Attractive Quality", in Park Dahlgaard, S.M., Dahlgaard, J.J. (Eds), Building People and Organisation Excellence, Proceeding of the 4th QMOD conference, Linköping, Sweden, pp. 18-36.

Khalifa, A. S. (2004), "Customer value: a review of recent literature and an integrative configuration", Journal of Management Decision, Vol. 42, No. 5, pp. 645-666

Liu, A.H., Leach, M.P., Bernhardt, K.L. (2005), "Examining customer value perceptions of organisational buyers when sourcing from multiple vendors", Journal of Business Research, Vol. 58, Issue 5, pp. 559-568.

Mochimoto, T., Ohfuji, T. (2005), "A Study on Quality Corresponding to Price", in JUSE (Ed), Quality Evolution - Way to Sustainable Growth, Proceeding of International Conference on Quality, TokyoJapan, II-5, pp. 1-12.

Moussatche, H., Languell, J. (2001), "Flooring Materials - Life Cycle Costing for Educational Facilities", Journal of Facilities, Vol. 19, No. 10, pp. 333-343.

Nicholls, J. (1993), "Customer Value in Four Steps", TQM Magazine, Vol. 5, No. 6, pp. 49-53

Oh, H. (1999), "Service quality, customer satisfaction, and customer value: a holistic perspective", Hospitality Management, 18, pp. 67-82.

Padula, G., Busacca, B. (2005), "The asymmetric impact of price-attribute performance on overall price evaluation", International Journal of Service Industry Management, Vol. 16, No. 1, pp. 28-54.

Setijono, D. (2005), "The concept of proactive quality cost: understanding quality costs in a value-context", in JUSE (Ed), Quality Evolution - Way to Sustainable Growth, Proceeding of International Conference on Quality (ICQ), Tokyo, Japan, IV-12, pp. 1-13.

Simpson, P.M., Siguaw, J.A., Baker, T.L. (2001), "A Model of Value Creation", Journal of Industrial Marketing Management, Vol. 30, pp. 119-134.

Spitteri, J.M., Dion, P.A. (2004), "Customer value, overall satisfaction, end-user loyalty, and market performance in detail intensive industries, Industrial Marketing Management, 33, pp. 675-687.

van der Haar, J.W., Kemp, R.G.M., Omta, O (S.W.F). (2001), "Creating value that cannot be copied", Industrial Marketing Management, 30, pp. 627-636.

Wood, N. (2004), "Customer value: applying the first principle of lean", Management Services, Vol. 48, No. 3, pp. 14-17.

Woodsworth, H.M. (2000), Statistical Process Control, in Juran, J.M., Godfrey, A.B. (Eds), Juran's Quality Handbook, 5th edition, McGraw Hill.

\section{LIST OF FIGURES}

Figure 1

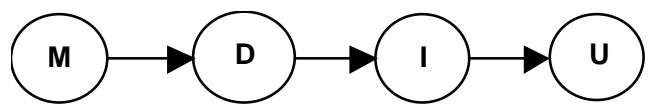

Figure 2 


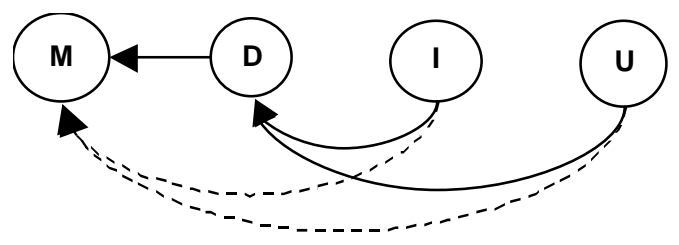

Figure 3

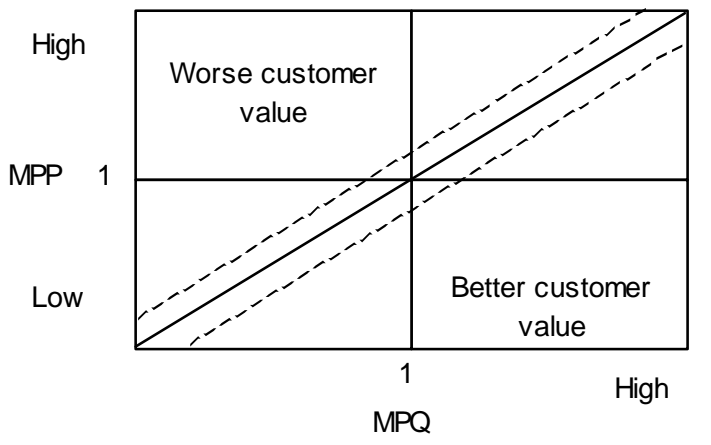

Figure 4

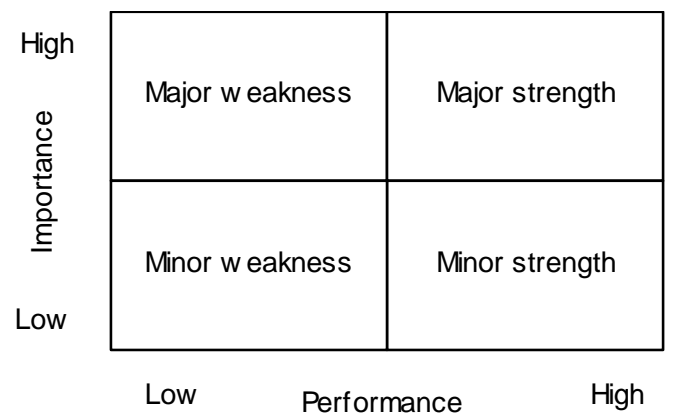

Figure 5

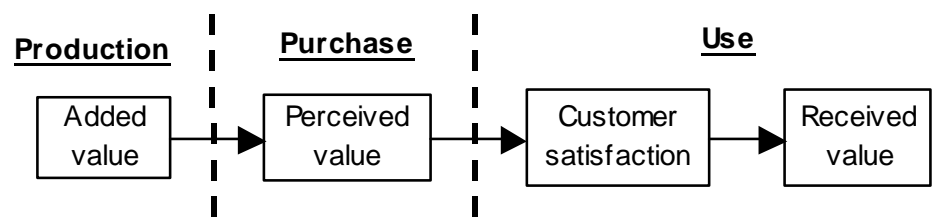

Figure 6

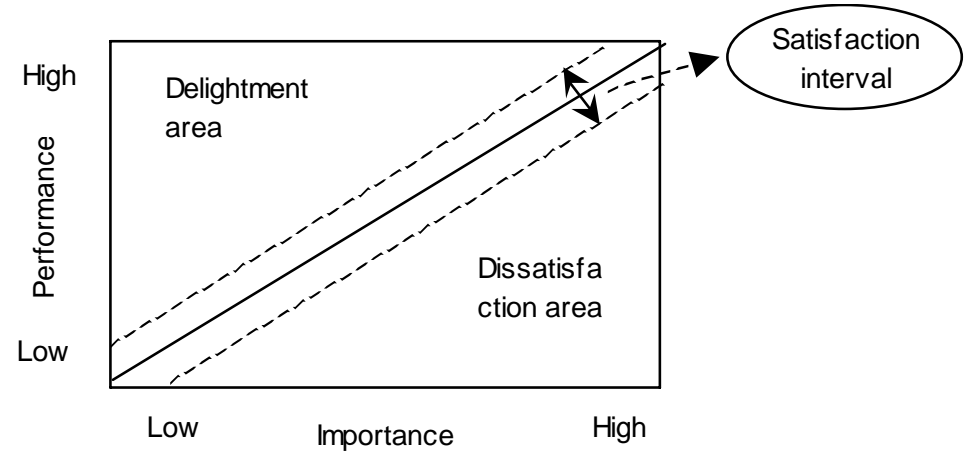


Figure 7

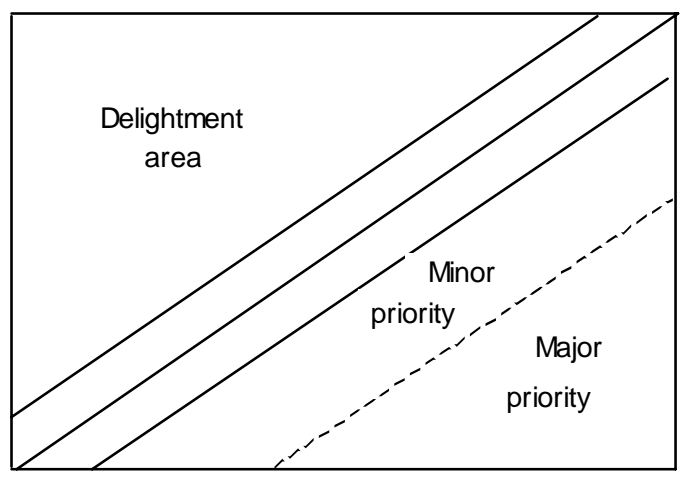

Figure 8

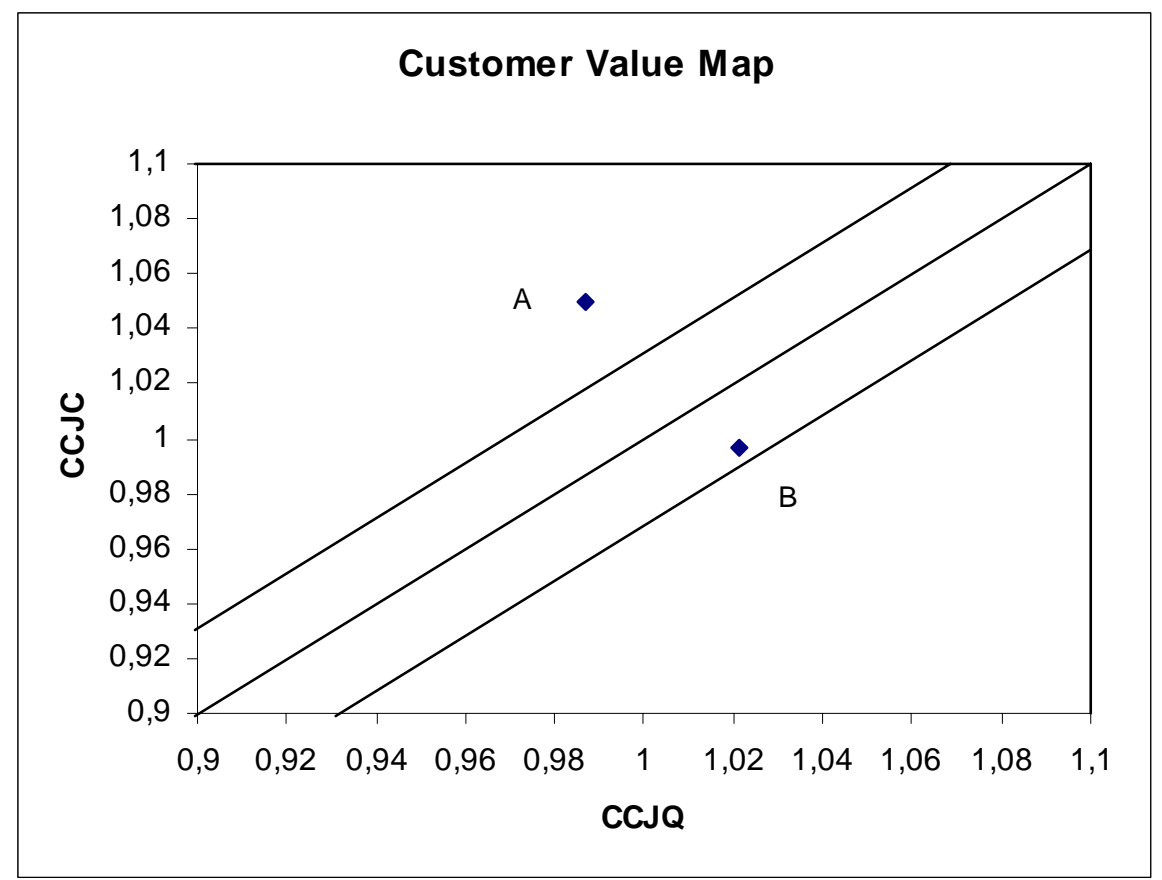

Figure 9

\section{Control chart to plot multiple quality attributes}

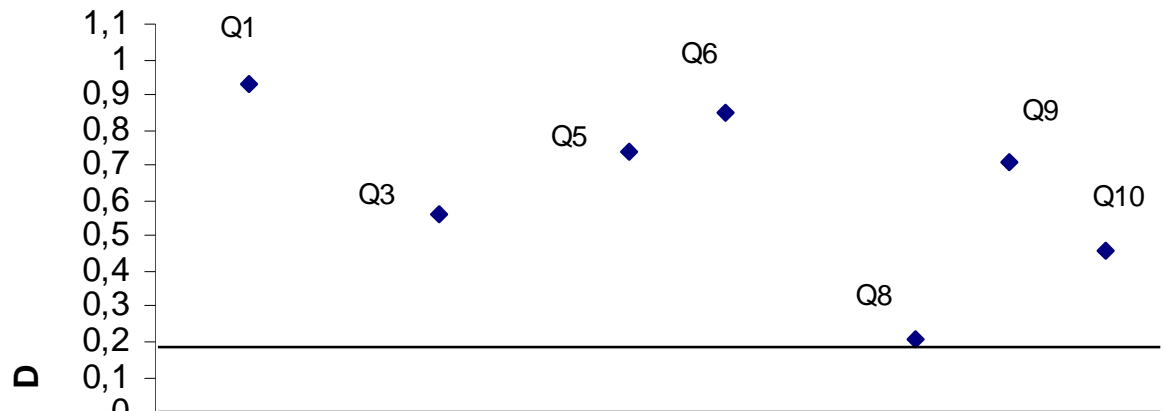


Figure 10

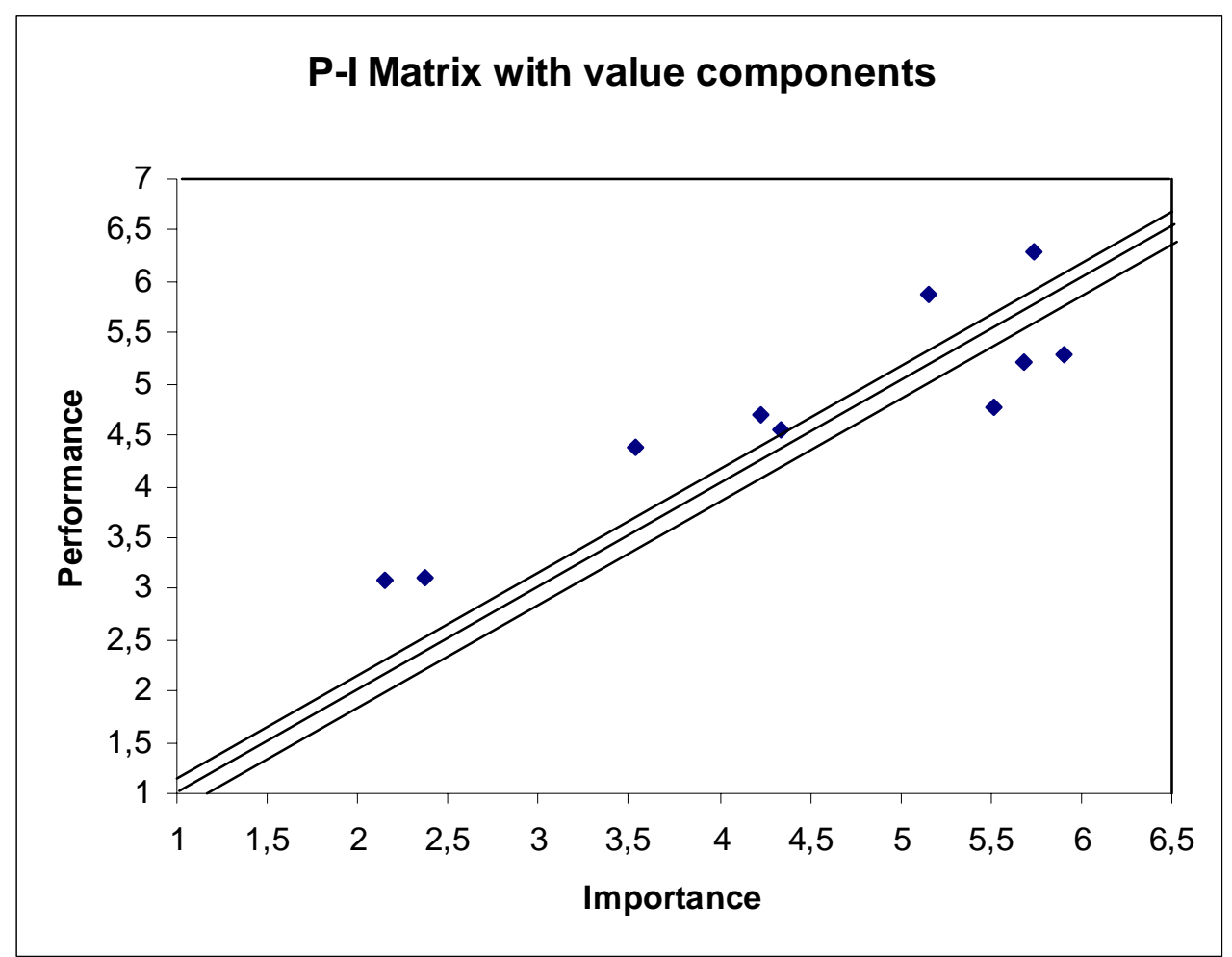

Figure 11

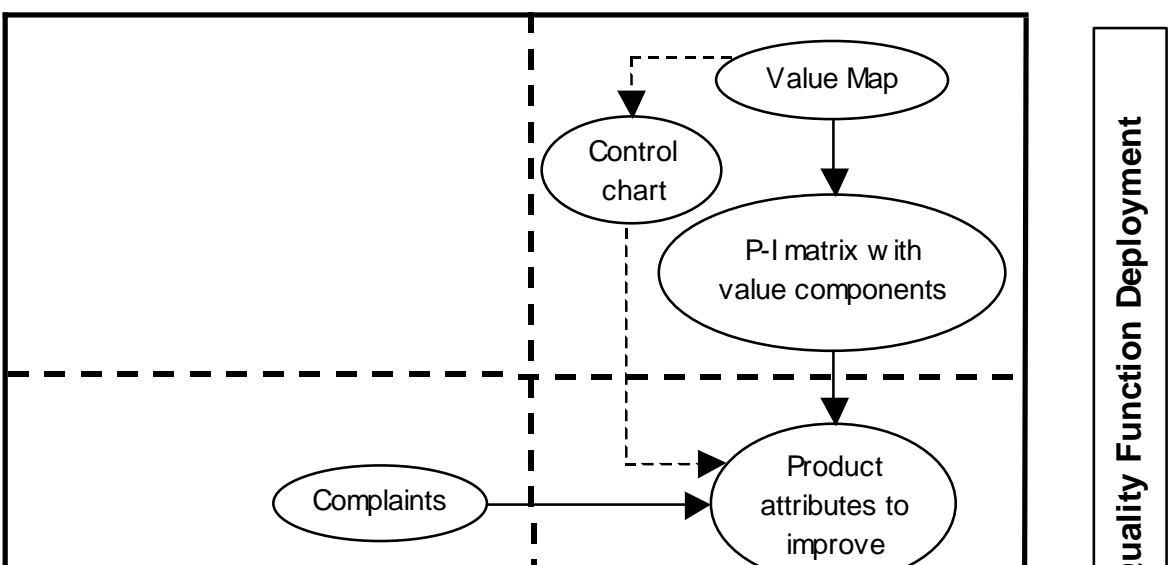




\section{LIST OF TABLES}

Table I

\begin{tabular}{cccl}
\hline MPQ & U/P & MPP & \\
\hline 0.92 & 0.97 & 0.95 & \\
1 & 1 & 1 & (Base value) \\
1.08 & 1.04 & 1.04 & \\
\hline
\end{tabular}

Table II

\begin{tabular}{cccc}
\hline & MPQ (x-axis) & MPP (y-axis) & Equation \\
\hline Upper value line & 0.92 & 0.95 & $\mathrm{y}=\mathrm{x}+0.03$ \\
Line of fair value & 1 & 1 & $\mathrm{y}=\mathrm{x}$ \\
Lower value line & 1.08 & 1.04 & $\mathrm{y}=\mathrm{x}-0.04$ \\
\hline
\end{tabular}

Table III

\begin{tabular}{ccccc}
\hline Attribute & Importance A & Performance A & Importance B & Performance B \\
\hline Q1 & 2.15 & 3.08 & 3.02 & 3.47 \\
Q2 & 5.68 & 5.21 & 5.68 & 5.37 \\
Q3 & 5.74 & 6.30 & 5.74 & 6.27 \\
Q4 & 5.51 & 4.78 & 5.51 & 5.78 \\
Q5 & 2.37 & 3.11 & 3.37 & 3.56 \\
Q6 & 3.53 & 4.38 & 3.53 & 4.18 \\
Q7 & 5.91 & 5.28 & 5.29 & 4.87 \\
Q8 & 4.34 & 4.55 & 4.23 & 4.52 \\
Q9 & 5.16 & 5.87 & 5.16 & 5.67 \\
Q10 & 4.23 & 4.69 & 4.23 & 4.46 \\
& & & & \\
C1 & 3.22 & 3.58 & 2.25 & 2.87
\end{tabular}




\begin{tabular}{lllll} 
C2 & 4.19 & 3.61 & 4.17 & 3.86 \\
C3 & 4.63 & 4.84 & 5.94 & 6.19 \\
C4 & 5.18 & 4.79 & 3.41 & 3.52 \\
C5 & 3.78 & 4.32 & 3.71 & 3.92 \\
\hline
\end{tabular}

Table IV

\begin{tabular}{ccccc}
\hline Attribute & I_norm A & I_norm B & Sum & W \\
\hline Q1 & $\frac{2.15-1}{7-1}=0.192$ & 0.336 & 0.528 & 0.045 \\
Q2 & 0.780 & 0.780 & 1.560 & 0.133 \\
Q3 & 0.790 & 0.790 & 1.580 & 0.135 \\
Q4 & 0.752 & 0.752 & 1.503 & 0.128 \\
Q5 & 0.228 & 0.395 & 0.623 & 0.053 \\
Q6 & 0.422 & 0.422 & 0.843 & 0.072 \\
Q7 & 0.818 & 0.715 & 1.533 & 0.131 \\
Q8 & 0.557 & 0.538 & 1.095 & 0.093 \\
Q9 & 0.693 & 0.693 & 1.387 & 0.118 \\
Q10 & 0.538 & 0.538 & 1.077 & 0.092 \\
& & Total & $\mathbf{1 1 . 7 3 0}$ & $\mathbf{1}$ \\
C1 & 0.370 & 0.208 & 0.578 & 0.114 \\
C2 & 0.532 & 0.528 & 1.060 & 0.209 \\
C3 & 0.605 & 0.823 & 1.428 & 0.281 \\
C4 & 0.697 & 0.402 & 1.098 & 0.216 \\
C5 & 0.463 & 0.452 & 0.915 & 0.180 \\
& & Total & $\mathbf{5 . 0 8 0}$ & $\mathbf{1}$ \\
\hline
\end{tabular}

Table V

\begin{tabular}{cccc}
\hline Attribute & $\mathbf{W}$ & $\mathbf{R}$ & $\mathbf{W}^{*} \mathbf{R}$ \\
\hline Q1 & 0.045 & $\begin{array}{c}3.08 / 3.47 \\
0.888\end{array}$ & 0.040 \\
& & 0.970 & 0.129 \\
Q2 & 0.133 & 1.005 & 0.136 \\
Q3 & 0.135 & 0.827 & 0.106 \\
Q4 & 0.128 & 0.874 & 0.046 \\
Q5 & 0.053 & 1.048 & 0.076 \\
Q6 & 0.072 & 1.084 & 0.142 \\
Q7 & 0.131 & 1.007 & 0.094 \\
Q8 & 0.093 & 1.035 & 0.123 \\
Q9 & 0.118 & 1.052 & 0.097 \\
Q10 & 0.092 & CCJQ & $\mathbf{0 . 9 8 7}$ \\
& & 1.247 & 0.142 \\
C1 & 0.114 & 0.935 & 0.195 \\
C2 & 0.209 & 0.782 & 0.220 \\
C3 & 0.281 & 1.361 & 0.294 \\
C4 & 0.216 & 1.102 & 0.199 \\
C5 & 0.180 & CCJC & $\mathbf{1 . 0 5 0}$ \\
\hline
\end{tabular}

Table VI 


\begin{tabular}{cccc}
\hline Attribute & $\mathbf{W}$ & $\mathbf{1} / \mathbf{R}$ & $\mathbf{W} * \mathbf{1} / \mathbf{R}$ \\
\hline Q1 & 0.045 & 1.127 & 0.051 \\
Q2 & 0.133 & 1.031 & 0.137 \\
Q3 & 0.135 & 0.995 & 0.134 \\
Q4 & 0.128 & 1.209 & 0.155 \\
Q5 & 0.053 & 1.145 & 0.061 \\
Q6 & 0.072 & 0.954 & 0.069 \\
Q7 & 0.131 & 0.922 & 0.121 \\
Q8 & 0.093 & 0.993 & 0.093 \\
Q9 & 0.118 & 0.966 & 0.114 \\
Q10 & 0.092 & 0.951 & 0.087 \\
& & $\mathbf{C C J Q}$ & $\mathbf{1 . 0 2 1}$ \\
C1 & 0.114 & 0.802 & 0.091 \\
C2 & 0.209 & 1.069 & 0.223 \\
C3 & 0.281 & 1.279 & 0.359 \\
C4 & 0.216 & 0.735 & 0.159 \\
C5 & 0.180 & 0.907 & 0.163 \\
& & CCJC & $\mathbf{0 . 9 9 6}$ \\
\hline
\end{tabular}

Table VII

\begin{tabular}{cc}
\hline Attribute & $\mathbf{D}_{\mathbf{j}}$ \\
\hline Q1 & 0.93 \\
Q2 & -0.47 \\
Q3 & 0.56 \\
Q4 & -0.73 \\
Q5 & 0.74 \\
Q6 & 0.85 \\
Q7 & -0.63 \\
Q8 & 0.21 \\
Q9 & 0.71 \\
Q10 & 0.46 \\
\hline
\end{tabular}

